NBER WORKING PAPER SERIES

\title{
PRECEDENT AND LEGAL ARGUMENT IN \\ U.S. TRADE POLICY: DO THEY \\ MATTER TO THE POLITICAL ECONOMY \\ OF THE LUMBER DISPUTE?
}

Joseph P. Kalt

Working Paper No. 4749

\author{
NATIONAL BUREAU OF ECONOMIC RESEARCH \\ 1050 Massachusetts Avenue \\ Cambridge, MA 02138 \\ May 1994
}

This paper has been prepared for the conference on The Political Economy of Trade Protection, National Bureau of Economic Rescarch, February 1994. This draft is preliminary and for comment only. I have served as an economic consultant to the Governments of Canada and British Columbia in the "Lumber III" trade dispute and have benefitted greatly from access to the documentary record in that proceeding. Any errors or omissions are solely my own, as are the preliminary views set forth. This paper is part of NBER's research program in International Trade and Investment. Any opinions expressed are those of the author and not those of the National Bureau of Economic Research. 


\title{
PRECEDENT AND LEGAL ARGUMENT IN \\ U.S. TRADE POLICY: DO THEY \\ MATTER TO THE POLITICAL ECONOMY \\ OF THE LUMBER DISPUTE?
}

\begin{abstract}
For more than a decade, the United States and Canada have been engaged in a rancorous dispute over trade in softwood lumber. Through three successive rounds of administrative litigation before the U.S. Department of Commerce, the U.S. sawmill industry has sought to have countervailing duties imposed upon Canadian lumber imports. The U.S. interests argue that Canada subsidizes its sawmills by providing timber from public forests at below-market prices, and by restricting exports of Canadian logs.

The trade war over lumber is waged primarily in the hearing rooms of the Department of Commerce. The rules of war are set down in the legal criteria and precedents of U.S. countervailing duty (CVD) law, and both the U.S. and Canadian interests have invested heavily in legal armaments. This study examines whether, and to what extent, the institutional framework - the legal rules, standards and precedents - of CVD law influences the success or failure of the contending parties.

Two alternative theories of political economy are tested. Capture Theory de-emphasizes the role of institutional settings of the kind at work here: The outcomes of political action are determined by the stakes and organization of rent-seeking parties, and the quasi-judicial regulatory proceedings of the Department of Commerce are mere Stiglerian theater. The New Institutionalism, on the other hand, posits that the structure and form of such proceedings are conditioning constraints, with the capacity to significantly influence the outcome of rent-seeking battles. Applying pseudo-regression Boolean techniques to a set of the actual legal issues argued before the Department of Commerce, this study finds more support for Capture Theory than for the New Institutionalism. An issue with large stakes is never lost by the politically-favored party, even when legal precedent and the burden of argument is against the party's interest.
\end{abstract}

Joseph P. Kalt

John F. Kennedy School of Government

Harvard University

79 JFK Street

Cambridge, MA 02138 
PRECEDENT AND LEGAL ARGUMENT IN U.S. TRADE POLICY:

DO THEY MATTER TO THE POLITICAL ECONOMY OF THE LUMBER DISPUTE?

by

Joseph P. Kalt'

Kennedy School of Government

Harvard University

\section{INTRODUCTION: APPLYING RATIONAL POLITICAL ECONOMY TO THE U.S.- CANADIAN LUMBER DISPUTE}

Efforts by interested parties to secure trade protection are frequently carried out in the U.S. through the quasi-judicial regulatory framework of countervailing duty (CVD) law, as administered by the Department of Commerce (DoC). This framework structures at least the form and content of the arguments for and against requested CVD protection. At the same time, however, interested parties have other venues through which to make their case -- Congress, the White House, political channels within the Department of Commerce, and other potentially involved agencies. Parties who participate in the Department's litigation process often confess to perceptions that the process is a charade; that the hearings and filings before the Department's International Trade Administration (ITA) and International Trade Commission (ITC) have no 
influence on the ultimate policy outcomes. Instead, it is averred, the policy outcomes are driven by interest group politics, leaving the litigatory apparatus to serve merely as beside-the-fact packaging for decisions made elsewhere and through different, "purely political" processes. If this portrayal is true, the nation pays a high cost for "packaging."

This study tries to get at the questions of whether and how the quasi-judicial regulatory process by which CVD law is administered affects the success or failure of parties petitioning for protection. The research posits two primary, and one subsidiary, theories of the role that institutional structure plays in determining regulatory outcomes. These competing theories are then examined -- tested to the extent possible -- in the context of a particular set of cases that have been flowing into the Department of Commerce in recent years. These cases make up the on-going disputes over trade in lumber and logs -- the so-called "timber trade wars" -- that have been raging between the United States and Canada for a decade. ${ }^{2}$ As of 1992, the U.S. had imposed countervailing duties on Canadian softwood lumber imports on the grounds that the Canadians provide publicly-owned trees to loggers at subsidized prices, and that Canadian log export restraints (LERs) subsidize the prices that Canadian sawmills pay for raw logs.

In order to get leverage on the concept of "institutions," this research focusses on the role that a particular legal institution -- legal precedent -- plays in determining the subgame successes and failures that contending parties have as they tussle over such matters as the applicability of CVD law, the definition of the relevant product and geographic markets affected by allegedly countervailable foreign subsidies, and the measurement of the magnitude of alleged

2 See Kalt, J., "The Political Economy of Protectionism: Tariffs and Retaliation in the Timber Industry" in R. Baldwin, Trade Policy Issues and Empirical Analysis, (University of Chicago Press: NBER, 1988). 
subsidies (and the attendant size of a countervailing duty). Legal precedent is treated as a costly "entry" barrier that litigants face when trying to exert political influence. Resources are expended by competing parties to defend or breakdown precedents in a stochastic process of "take your best shot [via legal argument] and hope you hit the bull's-eye." What arguments work and why?

Section II of this paper discusses alternative theories of the political economy of the administrative process of economic policymaking, focussing on so-called "capture theory" and "neo-institutionalist" explanations for the role of legal proceedings before the Department of Commerce's ITA. Section III then provides a brief background on the issues and stakes in the U.S.-Canada lumber dispute. Section IV discusses the testing methodology and specific hypotheses regarding the determinants of successful pleadings before the ITA. This section also sets out the specific arguments regarding a set of 14 key issues disputed by the contending parties in their arguments to the ITA. Section V implements the empirical tests, making use of newly developed methods for determining the informational content of small sample, dichotomous "cases." Section VI summarizes findings and pursues ramifications.

\section{COMPETING THEORIES OF THE ROLE OF INSTITUTIONS IN POLITICAL ECONOMY}

II.A Capture Theory and the New Institutionalism

At some risk of caricature, economic theories of rational political economy (or what used to be called the "economic theory of regulation") are currently pulling scholars into two broad camps: Capture Theory (CT) and the New Institutionalism (NI). Under the former, it is argued that political outcomes can be predicted and explained by a combination of two primary economic factors: (1) the differential stakes that contending parties have in a particular 
law or regulation, i.e., where the rents are; and (2) the differential costs of effective political organization that contending rent-seeking interest groups confront as a result of standard Olsonian forces of free riding. ${ }^{3}$ Within this framework, regulatory outcomes and processes are "captured" by successful interest groups who wield the most effective political influence, where "influence" is usually measured by either votes delivered to politicians or votes-plus-campaign-contributions delivered to politicians.

The New Institutionalism does not deny that the two primary factors underlying CT are indeed important (if not strictly "primary"), but adds a third fundamental explanatory factor to efforts to understand political outcomes. This factor is the institutional context -- laws, procedures, precedents, regulations, voting rules, etc. -- that forms the playing field upon which contending rent seekers meet. NI lays claim to every bit as much economic rationality in the modeling of political actors as does CT, but argues that institutional structure constitutes binding constraints, or at least conditioning costs, that limit the range of actors' investments in political outcomes and hence play determinative roles in political outcomes. ${ }^{4}$ Thus, to understand why, for example, the U.S. moved in 1992 to impose tariffs on imports of Canadian lumber, and why the tariff structure and rates are what they are, NI asserts it is necessary to understand the formal

3 The classic statements here are from the Chicago School: Stigler, G., "The Economic Theory of Regulation, "Bell J. of Econ. Spring 1971, 3-21; Peltzman, S., "Toward a More General Theory of Regulation," J. of Law and Econ., August 1976, 211-40; Becker, G., "Competition Among Pressure Groups for Political Influence," Quart. J. of Econ., August 1983, 371-98.

4 See, e.g., North, D., Institutions. Institutional Change, and Economic Performance (Cambridge Univ. Press: Cambridge, 1990); Bates, R., "Contra-Contractarianism: Some Thoughts on the New Institutionalism," Politics and Society, 16, 1988, 387-401; and the writings of the "rational political economists" (incl. Fiorina, Shepsle, Alt, et al.). 
institutional setting through which the U.S.-Canada lumber dispute has been mediated.

A fundamental divergence between $\mathrm{CT}$ and $\mathrm{NI}$ arises over the issue of the endogeneity (and speed of endogeneity) of political institutions. CT tends to view institutions as ephemeral: political actors have the ability to change political institutions; and if a capturing interest group needs an institution changed in order to garner wealth through political influence, support-seeking political actors will change that institution. NI, on the other hand, views political institutions as more exogenous: certainly they can be changed, but in any particular case (say, of regulatory agency behavior), it is costly to change institutions and such costs make institutions "sticky." This stickiness reflects rational commitment on the part of agents (e.g., Congress) to a governmental structure that can substitute for perfect monitoring by principals (i.e., voters and interest groups), but which is therefore imperfect and open to inertia, principal-agent-subagent slack, ideological considerations, etc.

In a nutshell, it is CT which argues, e.g.: "It doesn't matter who is President or if we reform Congress; policies will be driven by the underlying economic interests of effectively organized interest groups." NI responds: "Those interest groups have to work through an institutional context that can't be changed overnight and will make them more or less powerful in influencing the President or Congress or an administrative agency."

As these theories play out in investigation of a particular class of political actions, such as decisions of the ITA and the ITC regarding trade protection for U.S. lumber interests, they carry testably different implications. According to $\mathrm{CT}$, institutions such as legal proceedings are "Stiglerian theater": the real game is being played out behind the scenes of the hearing rooms by interest groups and support-maximizing politicians. Legal rulings and such matters as 
precedent may be a language by which the game is explained or justified after-the-fact to appease the press and the public, but is not determinative of outcomes. NI would hold, however, that such institutions as precedent, standards of evidence, and burdens of proof matter: Agency decision makers and the judges can't simply ignore precedent, evidence, or procedure, no matter how much political clout the beseeching interest group has. If a group does not have a good argument by which to satisfy or overcome precedent, or meet its evidentiary burden, it runs the risk of losing before the agencies and the courts.

\section{II.B. Research Design}

These descriptions of Capture Theory and the New Institutionalism present them as sharply distinct, alternative hypotheses. As in many contexts where the demands of research are to isolate testable differences in hypotheses, however, the differences here are drawn too starkly. The added ingredient of NI - the determinative role of institutional structure -- is not at odds with the rational, choice-theoretic underpinnings of $\mathrm{CT}$, and $\mathrm{CT}$ defenders might surely agree that in any particular instance of economic policymaking, institutions can matter. The link is suggested above: the principal-agent problem readily generates institutional structure as a constraint on agents that principals (such as members of the Congress) rationally adopt when they are "captured" every bit as much as implied by $\mathrm{CT}$, but can only imperfectly monitor how well their agents (such as the regulatory agencies) are doing at the kind of constituent support maximization that underlies $\mathrm{CT}$. $^{\text {s }}$

Recognizing these intersections of CT and NI, the tests proposed here must be

3 The nature of such support maximization is worked out for the case of no principal-agent slack by, e.g., Peltzman, op. cit. and Becker, op. cit. 
thought of more modestly than "testing CT versus NI." Rather, the objective of this study is to see whether the added ingredient of NI - the institutional structure of the legal proceedings by which CVD decisions are made in the U.S. -- adds significantly to our understanding of the political economy of the particular case of the U.S.-Canada lumber dispute.

The discussion of sections I and II.A suggests the outlines of a research design by which to understand whether and how the quasi-judicial litigatory process of CVD law administration influences the success or failure of requests for protection. Specifically, the research results reported below attempt to systematically examine a moderately-sized sample of actual legal arguments made before the ITA in the U.S.-Canadian lumber dispute in order to test whether or not success in making an argument can be systematically explained as a function of determinants of the severity of the beseeching party's precedential burden or other contextual aspects of the legal proceedings (per NI theory). Or, alternatively, is success or failure unrelated to apparent precedential burdens and institutional context of the legal proceedings (per CT theory)?

The testing of NI against $\mathrm{CT}$ in the case at hand begins with identification of salient attributes of the CVD legal proceeding before the ITA, and then tests whether variation in those attributes across a range of issues argued before the ITA provides explanation for variation in ITA decisions -- where "variation in ITA decisions" refers to whether the "winner" in a particular argument is the pro-CVD party (U.S. lumber interests) or the anti-CVD party (the Canadian parties). Under U.S. law (conditioned by various Trade Acts and U.S. participation in the GATT), parties seeking to establish tariff protection for U.S. industries under the rules governing countervailing duties do so by initiating a legal petition before the International Trade 
Administration. The ITA's core responsibilities in CVD proceedings is to determine whether, in fact, the targeted foreign government is engaging in a countervailable subsidization of its home industry and, if so, by how much (commonly measured as the net reduction in cost realized by the subsidized sector). On a separate legal track, the International Trade Commission has the responsibility of determining whether the U.S. industry of interest has been injured as a result of the asserted countervailable subsidy. Should a party prevail at the ITA and the ITC, countervailable duties are then normally imposed unless blocked by the President under oversight executive powers reserved to the office under U.S. law.

Upon acceptance of a CVD petition for consideration, legal proceedings are launched whereby the ITA first gathers information regarding the nature (e.g., legal origin, method of payment, and level of production) and extent (e.g., magnitude and coverage within and across industries) of any purported subsidy by a foreign government. Interested parties typically include the U.S. industries which compete with the allegedly-subsidized foreign industries, the affected foreign industries, and the foreign government. ${ }^{6}$ The ITA itself can be a party to the dispute by self-initiating CVD inquiries. Although the particular vehicles of participation can depend upon legal criteria of standing, interested parties typically have the ability to participate in the formal ITA proceedings, providing information and legal and substantive argument through the written submissions, provision of data, and oral statements of expert witnesses, industry participants, and legal counsel. Following a round of initial submission and consideration, the

6 Interestingly, U.S. consuming interests are typically absent from formal ITA proceedings - in keeping with the predictions of CT that the very wide dispersal of their interests and low per capita stakes leave them unable to overcome Olsonian free rider problems and become a cohesive interest group. 
ITA issues a Preliminary Determination to which parties with standing can reply. Following replies and further consideration, the ITA then typically issues a Final Determination. As a result of the Free Trade Agreement between Canada and the U.S., Final Determinations in CVD proceedings such as the lumber dispute are referred for appeal and review to a five member binational panel.

I wish to focus here on the Final Determination phase of CVD proceedings, wherein the International Trade Administration of the Department of Commerce makes its key rulings and sets forth and imposes specific duties. To this point in CVD proceedings, the ITA is the key adjudicator of parties' disputes, with its procedural, policy, and evidentiary standards codified in law and precedent. In most cases, the key decisions leading to imposition of protective tariffs on behalf of domestic industries are made at this level; a doctrine of "deference to the agency" makes it very difficult for an appealing party to overturn the ITA's findings, particularly on matters of factual evidence.

The doctrine of legal "precedent" sits at the institutional heart of ITA (and other regulatory agency) legal proceedings. When prior rulings of the agency or appellate bodies overseeing the agency have established particular procedural, policy, or evidentiary standards, such standards play central roles in determining the burdens and natures of proof that a party must satisfy in order to justifiably prevail in an argument. Precedent (and tinc doctrines of legislative intent and due process upon which it is based) thus conditions the ability of a party to win an argument. Where precedent has established a high burden of proof for a party, for example, the likelihood of prevailing declines. Where precedent has created a strong legal principle, securing a ruling contrary to that principle is less likely. 
Within the framework of the New Institutionalism, precedent can be represented as exerting two kinds of influences on the outcome of regulatory policymaking. First, for a given precedent, a party seeking a ruling contrary to that precedent should require particularly strong arguments. "Strong," here, is contextual; and "should" means "if NI is adding to our understanding of the outcome of the policy process." If the precedent, for example, concerns evidentiary thresholds (which can range from a standard of a "more than a mere scintilla" of the evidence to "beyond a reasonable doubt"), the party to whom precedent assigns the burden of proof should require more clear-cut, fewer controvertible facts which fit that theory, and/or clearer exposition in order to win the argument at issue as the height of the burden increases.

Second, precedents, themselves, can vary in strength. U.S. administrative law changes over time. Congress modifies underlying legislation; appellate bodies clarify or modify previous rulings; administrative agencies exercise latent discretion; and so on. Experience in the administrative law process, however, indicates inertia and variation in the mutability of various precedents. Within the New Institutionalism, precedents should be "stronger" -- i.e., harder for an opposing party to overcome, or easier for a supporting party to uphold -- the longer and more frequently that have withstood previous challenges and been reaffirmed by appropriate authorities, and the more clear is the underlying legislative intent and/or directive.

In short, relative to Capture Theory, the New Institutionalism predicts that:

NI-1. For a given precedent, variation in the ability of a party to overcome that precedent or meet the burden of that precedent should be positively related to the strength of that party's arguments.

NI-2. Variation in the ability to overcome precedents or meet the burdens of precedents should be positively related to variation in the strength of relevant precedents.

With the kinds of definitions of "strength" discussed above (and elaborated below), these two 
hypotheses form the testable difference between $\mathrm{CT}$ and NI in the context at hand.

Under strict CT, variation in the success or failure of a party's arguments should not depend on contextual attributes of the institutions of precedent. Rather, variation in the success of arguments ought to be related to the stakes of the contending parties:

CT-1. The decision maker should be more likely to award a victory to an argument the larger the stakes of the beseeching party, independent of the strength of the party's arguments and the strength of the precedent at issue.

In the proceeding under examination, on any given issue, it is the case that the magnitude of one party's gain is (to a first approximation) also the opponent's loss; stakes are generally of equal but opposite sign from the contending parties' perspectives Across issues, however, stakes differ in their magnitude. An issue such as the very existence of a countervailable subsidy is an all-ornothing matter, while disputes over measurement of marginal adjustments to a purported subsidy put less at stake for the contending parties. Within the kind of equalize-support-at-the-margin version of CT developed by Peltzman" and Becker?, support-seeking principals (and their agents) faced with support-offering constituents of unequal political clout should secure support from disparate parties by arriving at regulatory decisions that differentially favor the more influential party, but that do not cut the less influential party completely out. ${ }^{10}$ This perspective on

7 Much of the research that is focussed on Capture Theory (as well as NI) is directed at variations in the ability of potentially-affected interest groups to organize and exert influence. In the present context, the hurdle of organization has already been overcome; the parties are already in the hearing room exerting whatever influence they have.

- See Peltzman, op. cit.

9 See Becker, op. cit.

10 This is the litigation analogue to the optimizing equilibrium demonstrated by Peltzman, op. cit., wherein the support-maximizing decision maker equates the marginal support 
argument CT-1 is implemented below.

These competing hypotheses, NT-1 and NT-2 versus CT-1, about how the ITA legal process works form the core of the analysis undertaken here. An illustration is helpful to explain the framework. The U.S. lumber industry has long argued that the Canadian federal and provincial governments provide the rights to cut trees ("stumpage" rights) at below-market prices to Canadian loggers, and that this constitutes a countervailable subsidy to lumber production in Canada. Economists testifying on behalf of the Canadians (e.g., Wm. Nordhaus of Yale University) and economists researching the matter independently (e.g., myself ${ }^{11}$ ) have argued that the evidence and the theory indicate that to the extent Canadian stumpage may be below-market, the consequence is merely an inframarginal transfer of Ricardian and Hotelling rent to loggers. The supply of logs and hence lumber is left unchanged. U.S. lumber producers, therefore, face no incremental competitive pressure from Canadian lumber producers and are not harmed by Canadian stumpage policy.

This argument has never gotten anywhere at the ITA or the ITC. It appears to be misunderstood and dismissed as irrelevant theorizing by university economists. Such appearances, however, do not justify any general conclusions regarding as to how the quasijudicial CVD process operates or as to which arguments take hold and which do not. In order to draw generalizable conclusions in this regard, systematic evidence must be garnered from a

gained from a decision favorable to group $\mathrm{A}$ to the marginal support lost as a result from group B.

" Kalt, J., "The Political Economy of Protectionism: Tariffs and Retaliation in the Timber Industry" in R. Baldwin, Trade Policy Issues and Empirical Analysis (University of Chicago Press: NBER, 1988). This research was undertaken and published prior to any engagement with any party to the lumber dispute. 
framework which isolates alternative determinants of what makes one argument take hold, while a another falls on deaf ears.

Below I identify a set of central, stakes-bearing issues that have been adjudicated by the ITA in the latest round of the U.S.-Canada trade dispute. These issues can be categorized according to who -- the U.S. petitioners or the Canadians -- has won each of them as of the ITA's Final Determination, reached in May 1992. This creates a dichotomous winner-loser variable by which to gauge the outcome of the legal proceedings. For each of the arguments in the data set, I then code the stakes at issue in the argument for their magnitude, and code the argument of the winning party for its consistency with precedent, its analytic or theoretical straightforwardness, the strength of the winner's evidence, and the ease of exposition entailed by the winner's argument. (These concepts are given more delineation below).

The objective is to create a data set that can be analyzed under the pseudoregression Boolean techniques pioneered by Ragin. ${ }^{12}$ These techniques permit dichotomous data sets representing panels of cases to be reduced to their logical meaning in terms of necessary and sufficient conditions in a manner that continuous variable econometric techniques, familiar to most economists and political scientists, are unable to do. If the cross-case tests for the two central hypotheses, NI-1 and NI-2, listed above are borne out, the results will be consistent with an NI view of the regulatory process. If their is no coherent pattern to the hypothesized explanatory factors except the stakes at issue, the results will be most consistent with CT theory

12 Ragin, Charles C., The Comparative Method, (Berkeley: Univ. of Calif. Press, 1987). 
(per CT-1). ${ }^{13}$

\section{III. "LUMBER III": HISTORY AND ISSUES}

The United States and Canada have been engaged in a long running dispute over softwood lumber imports from Canada into the U.S. These imports compete directly with lumber supplies produced in the United States, with sawmillers, in the Pacific Northwest region of Washington, Oregon, Idaho, and British Columbia most notably, going head-to-head for sales in North America and the Far East. In both the U.S. and Canada, the public sector owns vast forest resources that are provided to private sector loggers at fees known as "stumpage." As noted, U.S. milling interests have long complained that they pay market value for stumpage under auction procedures used in U.S. public sector sales, while Canadian formula-based stumpage is below market. Moreover, allege the U.S. interests, provincial and federal export restraints on log exports restrict the ability of foreign buyers to purchase logs in Canada for export and cause the prices paid for Canadian logs by Canadian sawmillers to be lower than they otherwise would be. ${ }^{14}$ Both alleged below-market stumpage and depression of log prices below free-trade levels are asserted to constitute countervailable subsidies to Canadian lumber producers.

III.A Lumber I, II, and III

The first round of the timber trade war -- "Lumber I" -- was commenced by a

${ }^{13}$ A third theory, Contractarianism (per the Buchanan tradition) might predict that the "truth will out" and that the correctness (absence of ambiguity) of an argument would be the only or the dominant explainer of Won and Lost.

14 Ironically, the United States has log export restraints of its own. 
CVD investigation of Canadian stumpage launched by the Department of Commerce in 1982. Lumber I ended with a final negative determination by the Department of Commerce (DoC) in 1983, with the DoC finding that stumpage rights were allocated in a way that failed to satisfy the technical legal criterion of "specificity" (which requires that a subsidy be provided to a specific enterprise or industry, or group of enterprises or industries, in order for such a subsidy to be countervailable.

Lumber $\Pi$ arose in 1986 in response to a petition for investigation by the Coalition for Fair Lumber Imports (CFLI), a trade organization and lobbying group representing (predominantly) small and medium-size U.S. sawmill companies. CFLI again sought to countervail the Canadian stumpage system. The Department of Commerce found on Preliminary Determination that the Canadian stumpage system was both "specific" (in the sense described above) and "preferential" (i.e., it "distorted" the marketplace for lumber by affecting the supply schedule of Canadian lumber). DoC set the countervailing duty rate for Canadian lumber imports at $14.5 \%$ ad valorem. The Lumber II CVD was effectively preempted, however, when escalating retaliatory threats by the Canadians compelled the U.S. and Canada to enter into a Memorandum of Understanding (MOU). The Lumber II MOU obligated Canada to impose a $15 \%$ fee on softwood lumber exports to the U.S. ${ }^{15}$

In 1991, Canada and a number of its provinces concluded that the MOU had been satisfied, and lifted the $15 \%$ export fee. The DoC's ITA immediately launched Lumber III, an investigation into the possibility that Canadian stumpage continued to constitute a countervailable

is See Kalt, op. cit., for a discussion and calculation of the international welfare effects of Lumber II. 
subsidy. At the invitation of the ITA, the Coalition for Fair Lumber Imports filed submissions arguing that Canada's log export restraints (LERs) also constitute a countervailable subsidy by Canada to its lumber producers. Various Canadian parties, led by the various provinces' forestry ministries, in turn intervened to plead their case as to why neither the stumpage system nor log export restraints constituted countervailable subsidies. The ITA found on Preliminary Determination in March 1992 that both Canada's stumpage system and its LERs were

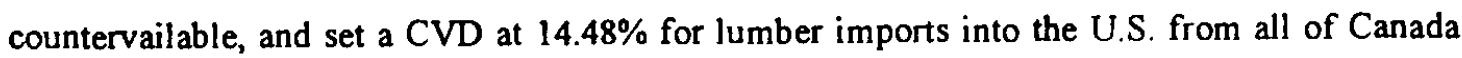
except the (volumetrically insignificant) Atlantic provinces. Following rounds of written and oral submissions by CFLI and the various Canadian governments, the ITA issued its Final Determination in May 1992.

On Final Determination in Lumber III, the ITA found both Canadian stumpage and the LERs to be countervailable, and set an ad valorem CVD of $6.51 \%$ for all Canadian lumber imported into the U.S. from Alberta, B.C., Ontario and Quebec. This CVD was a mixture of asserted stumpage and LER countervailable subsidy findings, with all affected provinces found to have stumpage subsidies. Only B.C. being found to have subsidies emanating from log export restraints; reflecting the geography and heterogeneous forest types of B.C., the asserted LER subsidy applied only with respect to logs produced along the dominant coastal regions of B.C. Following the Final Determination, Lumber III went before a bi-national panel for review and remand. The panel remanded the Final Determination back to the ITA for reconsideration and supplementation on a number of legal and evidentiary issues. The ITA then issued a Determination on Remand, raising the CVD to $11.54 \%$, with the increase coming primarily from the ITA's conclusion that the entire Province of B.C. constituted an integrated relevant log market 
and was thereby subject to the asserted LER subsidy.

The magnitude of the CVDs arrived at by the DoC may suggest that the stakes in the lumber dispute are small. However, duties on the order of $5 \%-15 \%$ translate into hundreds of millions of dollars annually. Lumber II, for example, concerned only stumpage, yet it has been estimated that its CVD would have produced (i.e., but for the MOU) tariff revenues of more than $\$ 340$ million per year for the U.S., and net gains for U.S. lumber producers of more than $\$ 400$ million per year. ${ }^{16}$ In the case of Lumber III, the stakes are summarized in Table 1 . The ITA's Final Determination estimates that the CVD would offset subsidies totalling close to $\$ 400$ million per year.

16 See Kalt, op. cit. 
Table 1

ITA ESTIMATES OF COUNTERVAUABLE

SUBSWIES:

FINAL DETERMINATION

(Millions of Dollars per Year)

\begin{tabular}{lccc} 
Province & Stumpage & $\begin{array}{c}\text { Log } \\
\text { Export } \\
\text { Restraints }\end{array}$ & Total \\
\hline Alberta & $\$ 5.1$ & $\$ 0$ & $\$ 5.1$ \\
B.C. & $\$ 145.7$ & $\$ 205.2$ & $\$ 350.9$ \\
Manitoba & $\$ 0$ & $\$ 0$ & $\$ 0$ \\
NW/Yukon & $\$ 0$ & $\$ 0$ & $\$ 0$ \\
Ontario & $\$ 34.3$ & $\$ 0$ & $\$ 34.3$ \\
Quebec & $\$ 0.1$ & $\$ 0$ & $\$ 0.1$ \\
Saskatchewan & $\$ 0$ & $\$ 0$ & $\$ 0$ \\
\hline TOTAL & $\$ 185.2$ & $\$ 205.2$ & $\$ 390.4$
\end{tabular}

In December 1993, the bi-national panel completed its review of the ITA's Determination on Remand and effectively found that neither Canadian stumpage nor B.C. LERs could be countervailed on the basis of the case developed by the ITA. The CVD was rejected and the matter remanded back to the ITA primarily on the grounds that it had not been shown that stumpage and the LERs were "specific" in the sense described above. As this is written, the ITA is preparing another Determination on Remand in response to the panel's December 1993 findings. The dispute over Canadian softwood lumber imports goes on.

III.B Framework for Boolean Representation of the Legal Arguments in Lumber III 
The legal proceedings engendered by Lumber III have undoubtedly increased the demand for logs in the world - by increasing the demand for paper. Hundreds of thousands of pages of legal briefs, official rulings, expert reports, hearing transcripts, correspondence, and data reporting have been produced and reproduced as the parties have argued their respective positions. In the course of the proceeding, a multitude of arguments have been put forth and debated. These arguments range from the legal and technical to the substantive and factual. Among the many arguments afoot, however, the focus of the proceedings in Lumber III has ended up being concentrated on a modest number of key matters. I now turn to a discussion of these for purposes of arriving at Boolean codings of their NI-attributes and CT-relevant attributes - precedential status, analytic straightforwardness, evidentiary strength, expositional hurdles, stakes, etc. I begin with an introduction to the applicable Boolean psuedo-regression techniques.

\section{III.B.I Boolean Logic and Pseudo-Regression Techniques}

Following the framework of section II, in the case at hand, we would like to see if and to what extent the success of an argument made in the legal context of the ITA's CVD procedures depends on such variables as the strength of the argument's analytic underpinnings, the strength of the precedent it encounters, the quality of the evidence in its favor, the stakes riding on it, etc. Such an analysis encounters significant methodological difficulties. Not the least of these is the creation of a metric by which to measure otherwise vague concepts such as the "strength" of precedent, or the "quality" of evidence. For social science researchers accustomed to continuous and naturally metered data (a good thing) and training that emphasizes the ideal of large sample sizes leading to quantitative measures of confidence etc. (a good thing, 
but only one quadrant of the philosophy of scientific method), measurement in a context of qualitative "cases" is commonly a dead end for production of useable research results. Indeed, in the legal contexts, questions such as "why did that party win its case?" are typically relegated to discursive case studies, to be published in law journals.

Pioneering (and prize-winning) methodological developments hold some promise for enabling the scientific researcher to isolate the useable information contained in comparative and qualitative "case studies." These methods of "Boolean Analysis" have been given modern social science impetus by (especially) Charles C. Ragin, and rely on the rules of logic and Boolean mathematics to parse out the useful information contained in such contexts." Notwithstanding unsettled questions regarding the epistemological relationship of these methods to more familiar methods of classical and Bayesian statistics, these methods do provide rigorous insight into the information content of otherwise qualitative cases.

The Boolean Analysis undertaken here relies upon the rules of logic to isolate qualitative causes of a dichotomous outcome. At its core, Boolean Analysis relies on logic of the following form to reach conclusions regarding the causal role of alternative postulated explanatory factors: suppose two causes, A and B, are postulated as explanations of an event, Y. A and B occur in various combinations of "presence" and/or "absence", and sometimes $\mathrm{Y}$ occurs. In an otherwise well-specified model of causation that identifies $\mathrm{A}$ and $\mathrm{B}$ as possible causes, if $A$ is always present when $Y$ occurs, but $Y$ occurs with $B$ present and with $B$ absent, $B$ can logically be eliminated as a necessary ingredient in the causation of $Y$. If the researcher can specify causal factors and determine their presence or absence across multiple instances of

17 See Ragin, op. cit. 
$\mathrm{Y}$ and not-Y, scientific information is gained through Boolean (presence/absence) logic of this form.

Boolean Analysis proceeds by coding an outcome of interest for Yes/No (zero/one) results. In the case at hand, for example, it is possible to examine the various arguments in Lumber III and determine objectively whether or not CFLI (or, alternatively, the Canadian parties) won or lost a particular dispute. Possible causal factors in determining when an outcome (e.g., "Win") occurs are then coded (zero/one) for their presence or absence in each observed instance in which an outcome occurs. (This "measurement" of "right-hand side" variables is the more difficult problem, and is taken up below.) The resulting coding can be represented by a Boolean Summary (or Truth) Table of the kind illustrated below.

\section{HYPOTHETICAL BOOLEAN SUMMARY TABLE}

(Upper Case $=$ Presence; Lower Case $=$ Absence)

\begin{tabular}{|c||c|c|}
\hline OUTCOME & FACTOR - A or a & FACTOR - B or b \\
\hline$Y$ & $a$ & B \\
\hline$Y$ & A & B \\
\hline$y$ & $a$ & $b$ \\
\hline
\end{tabular}

In this summary, Boolean Analysis would code the outcome $\mathrm{Y}$ in the first case (row) as $\mathrm{Y}=\mathrm{aB}$. The second case would be coded as $\mathrm{Y}=\mathrm{AB}$. Multiplication in Boolean analysis is read as "and", while addition is read as "or". Thus, we can say that $Y=a B+A B$; i.e., $\mathrm{Y}$ occurs when either " $\mathrm{a}$ " and " $\mathrm{B}$ " are present together or " $\mathrm{A}$ " and " $\mathrm{B}$ " are present together. If this is a well-specified model of the causation of $Y$, the result that $Y=a B+A B$ can be further reduced by factoring to $\mathrm{Y}=\mathrm{B}(\mathrm{a}+\mathrm{A})=\mathrm{B}$. In other words, $\mathrm{B}$ is a necessary and sufficient 
condition to cause $\mathrm{Y}$, and it doesn't matter whether $\mathrm{A}$ is present or not.

The expression from the illustration to the effect that $\mathrm{Y}=\mathrm{B}$ is a "prime implicant." Prime implicants indicate necessary and sufficient conditions in the following way:

$\begin{array}{ll}Y=B & B \text { is both necessary and sufficient. } \\ Y=A+B & A \text { and } B \text { are each sufficient, but not necessary. } \\ Y=A B & \text { Both } A \text { and } B \text { are necessary, but not sufficient. } \\ Y=A(B+C) & A \text { is necessary, but not sufficient. }\end{array}$

Note that Boolean Analysis of dichotomous factors is a form of "pseudoregression." This derives from the fact that, when two states, a and A, are both present when $Y$ occurs and other factors are constant across the relevant observations (i.e., B is present along with a and A), there is clearly a collinearity problem - $\mathrm{Y}$ occurs with both $\mathrm{A}$ and not-A. Just as with standard multiple regression techniques, the Boolean Analysis assigns a coefficient of "zero" to the $\mathrm{A} / \mathrm{a}$ factor because no causation can be attributed to it. Similarly, as with standard regression techniques, the validity of results from Boolean Analysis are dependent upon the outside-the-data specification that the researcher brings to the evidence. Specification bias can plague Boolean Analysis just as it plagues more familiar statistical approaches to isolating the effects of individual independent explanatory factors. Such bias could arise in the illustration if, for example, there were a left-out factor, $\mathrm{C}$, such that the accurate prime implicant was $\mathrm{Y}=\mathrm{aB}+$ $A B+A C$. In this circumstance, rejection of $A$ as a causal factor in explaining $Y$ would have been erroneous: A plays a causal role when it occurs along with $\mathrm{C}$.

For researchers accustomed to large sample, continuous variable analyses and hypothesis testing, the most obvious disadvantage of Boolean Analysis is the absence of quantitative measures of confidence in expressed results. At the same time, however, Boolean 
Analysis utilizes the rules of logical contradiction to arrive at epsitemologically valuable conclusions. ${ }^{18}$ Indeed, when problems of specification bias are not present, the ability of Boolean Analysis to yield statements regarding necessary and sufficient conditions represents an advantage over more familiar quantitative techniques (which focus primarily upon the marginal contributions of multiple variables).

As noted above, the coding of "left-hand side" variables in a case such as ITA's Lumber III Final Determination is largely objective and straightforward. It entails identifying the "winner" of a particular argument in the proceeding, as this is indicated in the actual ITA decision. Determining the presence or absence of particular possible causal factors that might explain an argument's success or failure, on the other hand, requires more judgement, and intensive reading of the appropriate legal records. Such investigation has required me to make certain qualitative assessments regarding, e.g., the straightforwardness of the economic theory of natural resource rent, but is bolstered by the fact that the final determinations enunciated by the ITA frequently provide direct discussion of such matters and the direction of influence on its findings. These yield the key "right-hand side" variables necessary for completion of an actual version of the hypothetical Boolean Summary Table shown above. The resulting variables and their expected influences (or "signs"), according to the ITA (by both direct assertion and argument passim) and bolstered by the reasoning from the $\mathrm{NI}$ interpretation of legal proceedings

18 Not to get too Kantian about the matter, but in so doing it might be argued that Boolean techniques in some circumstances can produce results that are more reliable than familiar quantitative methods provided the problem of specification bias is not present. Of course, this qualifier regarding: specification bias is equally applicable to the familiar techniques of quantitative analysis. See, e.g., Leamer, E., Specification Searches: Ad Hoc Inference with Non-Experimental Data (New York: John Wiley \& Sons, 1978). 
discussed above, are:

1. Precedent: Having precedent on one's side increases the likelihood of winning an argument. See discussion above. In the Boolean Analysis which follows this factor is referred to as $\mathrm{P} / \mathrm{p}$.

2. Straightforward Theory: Having a straightforward theory (e.g., an economic explanation or theory) improves the likelihood of winning an argument. Apparently, having to resort to complicated or exotic theories to make one's case reduces credibility (where "complicated," "exotic," etc. refers, in part, to being outside the familiar modes of reasoning of the ITA). Examples discussed below include the concepts of general equilibrium and natural resource rent, which modify familiar supply-demand reasoning. In the Boolean Analysis which follows this factor is referred to as $T / t$.

3. Evidence: All else equal, having the preponderance of evidence on one's side increases the likelihood of winning an argument. In the Boolean Analysis which follows this factor is referred to as $\mathrm{E} / \mathrm{e}$.

4. Ease of Exposition: All else equal, the likelihood of winning an argument increases with the ease with which it can be communicated. This is sometimes related to, but is not the same as, having a straightforward theory. An example from below is the Law of One Price, which is relatively easy to express as the intersection of a supply and a demand curve, but which is quite complicated to explain in application to real world factual contexts (owing to the introduction of considerations of the Law's underlying pre-conditions related to transactions costs, quality differentials, cross-elasticities, and the like). In the Boolean Analysis which follows this factor is referred to as $\mathrm{X} / \mathrm{x}$.

In addition to these factors, CT suggests that the stakes riding on an argument can influence the

likelihood of winning. In general, the ITA could not be expected to refer to this since the justice

it administers is "blind." Nevertheless,

5. Stakes: Assuming CT, the likelihood of the winning argument being made by the more influential party increases with the stakes at issue in the argument. In the Boolean Analysis which follows this factor is referred to as S/s.

III.B.2 The Arguments in Lumber III 
I now turn to coding the foregoing factors for a set of 14 actual and salient arguments that parties have contended over in Lumber III. The arguments and the results of the coding are set forth in Table 2. The Table also indicates the winning party in each argument as reflected in the ITA's Final Determination. Recalling that the Lumber III investigation was initiated by the Department of Commerce, the proceeding has presented a recurring difficulty in distinguishing between the DoC's role as advocate and its role as adjudicator. Indeed, this has led to formal claims of bias on the part of the Canadian parties. ${ }^{19}$ The resulting ambiguity is reflected in the "DoC/CFLI" designation of winner as applicable in Table 2. For each of the issues that follow, the $0 / 1$ codings shown in Table 2 are derived from the written record of the Lumber III proceeding. A brief summary of each issue is provided here.

1. Rent Theory: As discussed above, the economics of natural resource harvesting have played an important role in the Canadian response to allegations that the Canadian stumpage system subsidizes the production of lumber by Canadian millers. Obviously, the stakes here are very large (see Table 1); if the Canadians were to prevail in demonstrating that the effects of below-market stumpage were entirely inframarginal, the stumpage CVD would be unsupportable. Moreover, the only concerted evidence to test the inframarginality of Canadian stumpage pricing was that developed by Nordhaus on behalf of the Canadian parties. The economic theory of rent, however, is not straightforward, nor easily communicated. There apparently is not strong precedent one way or the other as to the applicability or legitimacy of rent theory in CVD proceedings.

19 The primary claim arises as a result of the fact that ITA has employed a former spokesperson for CFLI in the Lumber III investigation. 
2. LER as Subsidy: So-called "border measures," such as log export restraints have had an unsettled history in the administration of U.S. CVD law. Prior to a single ruling in 1990, border measures had been held to be noncountervailable. This placed the DoC/CFLI at a precedential disadvantage in its arguments for the countervailing of Canada's LERs. In fact, the DoC had to go so far as to argue that: "Administrative agencies, however, are authorized to depart from a long-standing and consistent practice...[and] the Department concludes that the [pre-1990 case] determinations finding border measures in general to be per se noncountervailable pursuant to U.S. law were wrongly decided..." ${ }^{20}$ Clearly, the stakes were all-or-nothing, and the DoC/CFLI was compelled to labor hard to muster what evidence it could in its favor (eventually appealing to its interpretation of Congressional intent). Exposition by the eventual winner, DoC/CFLI, was similarly impeded; and the theory as to why border measures are or ought to be countervailable is not straightforward - at either the ITA or in the broader context of GATT and trade - as they confront difficult issues of national sovereignty and measurement.

3. Market Distortion: In some prior proceedings, the DoC had indicated that CVDs are justified only when another country's alleged subsidies to domestic processors distort the results of the marketplace in an inefficient direction. In the case at hand, Canadian LERs may, in fact, improve world resource allocation. Evidence is consistent with the

20 Note that I do not intend to be asserting the rightness or wrongness of the positions taken by the parties on this or any other matter listed here. Rather, as this instance indicates, relative to many other issues in the proceeding, the DoC was having to argue very hard in order to make its precedential points; i.e., the precedential burden in practice did not favor its arguments. The quoted passage is from U.S. Department of Commerce, International Trade Administration, Final Countenvailing Duty Determination: Certain Sofnwood Lumber Products from Canada, May 15, 1992, pp. 176-77. 
conclusion that U.S. log export restraints and Japanese barriers to trade in lumber (of which Japan is nevertheless a major importer) artificially prop up (especially) Japanese demand for Canadian logs. Canada's LERs counteract this distortive result effect.

4. LER Price Change: In the initial stages of the Lumber III proceeding, the CFLI, in particular, maintained that the asserted subsidy realized by B.C. sawmills as a result of LERs should be measured as the difference between a measured foreign price of logs and a measured Canadian domestic price of logs. Precedent, however, seems to support the view that a countervailable subsidy must be measured by difference between the price that Canadian millers would pay for logs absent the LERs and the price they presently pay. Because of general equilibrium effects when a border measure is imposed on an intermediate product ${ }^{21}$ and the large-country position of Canada in wood fiber trade, it would generally be expected that foreign log prices would come down toward Canadian domestic prices in the absence of LERs - making the CFLI measurement contrary to precedent.

5. General Equilibrium Efrects - Their Existence: As noted, economic theory (and evidence in Lumber III) indicates that the context of Canadian LERs makes it highly likely that general equilibrium effects (between log markets and lumber markets) play significant roles in determining log prices. Although the measurement of the quantitative differences between partial and general equilibrium prices for logs absent Canadian LERs is complicated in theory and difficult to demonstrate and explain, the existence of general

${ }^{21}$ See, e.g., Wiseman, C.A. and R. Sedjo, "Effects of an Export Embargo on Related Goods: Logs and Lumber," American Journal of Agricultural Economics, August 1981, pp. 423 429. 
equilibrium effects is relatively straightforward and easy to communicate (e.g., "The LERs may not affect total log demand in B.C.; they may only affect where the Japanese have the logs that they buy milled.")

6. General Equilibrium Effects - Their Measurement: See above. Both the theory of the proper structure of a model able to capture general equilibrium effects and the implementation of such a model for the purpose of measuring the no-LER price of Canadian logs is complicated and difficult to describe in the context of the ITA's legal proceedings. ${ }^{22}$ Based on what evidence is available, the magnitude of the stakes is likely to be perceived as large by the ITA.

7. Causation Tests: Because border measures are indirect in their potential effects, the Canadian LERs' effects on Canadian millers' costs are not directly observable (as they would be if, say, subsidies were paid in cash to millers). Nevertheless the ITA is under a burden to demonstrate a "direct and discernable" impact of the LERs on Canadian sawmillers' costs. In the previous border measure case of 1990 (noted above), the ITA employed regression analyses of the differences between foreign and domestic prices to meet its burden. Notwithstanding the resulting precedential implications and the all-ornothing stakes, the ITA in Lumber III eschewed its previous approach (and evidence generated therefrom).

8. Other Provinces: Although other provinces besides British Columbia are subject to

22 See, for example, Wiseman and Sedjo, op. cit., and Moschini, G. and K.D. Meilke, "Production Subsidy and Countervailing Duties in Vertically Related Markets: The HogPork Case Between Canada and the U.S.," American Journal of Agricultural Economics, November 1992, pp. 951-61. 
LERs, they are relatively minor participants in the marketplace for wood fiber. Moreover, both straightforward theory and accompanying evidence seem to indicate that LERs in the other provinces are not generally economically binding (e.g., some are net importers of logs themselves). The implications are bolstered by the "direct and discernable" standard noted above, and by the ease of exposition.

9. Law of One Price: In lieu of hypothesis tests and statistical measurement of the magnitude of price effects attendant to LERs, the ITA relies on a partial equilibrium spreadsheet model that utilizes elasticities of supply and demand for an aggregated foreign log-only sector and a Canadian log-only sector to calculate a unique price at which foreign and B.C. log prices would be equated in the absence of Canadian LERs. This approach is justified by what DoC/CFLI refers to as the "universally accepted Law of One Price;" and despite considerable evidence that the conditions required for the Law to hold in the strong form adopted by the ITA do not apply even within "free trade" regions (such as western Washington). Without the Law, however, the DoC/CFLI would run the risk having no mechanism for identifying and calculating an asserted subsidy. In its favor, the DoC/CFLI have ease of exposition when compared to the Canadians' need to turn to more complicated theories that presumably sound like quibblings as about qualifications to the Law (see above).

10. Relevant Market/1: As noted above, the ITA's Final Determination in Lumber III found that logs in the interior of B.C. were not in the same relevant market as the rich forestlands of the coastal region (as a result of species heterogeneity, limited crosselasticities of demand, and high transport costs). The Canadian's case for this conclusion 
was built up from detailed evidence and extensive discussion of theory and evidence. In their favor, the "direct and discernable" burden faced by the DoC/CFLI created a favorable precedential for the Canadian view: the ITA's spreadsheet model used to identify and measure a subsidy to coastal B.C. log prices was built only for the coastal region. The stakes surrounding the treatment of the interior of the province are large; upon including the interior in its eventual Remand Determination, ITA raised the calculated value of the countervailable LER subsidy from the figure shown in Table 1 to more than $\$ 450$ million per year.

11. Relevant Market/2: The exclusion of interior logs from the subsidy calculation under the Final Determination represents the only identifiable case in which the Canadian interests have prevailed before the ITA on an argument with large stakes. While the ITA's eventual reversal in its Remand Determination is outside of the "Final Determination" framework upon which I am primarily focussed, it is included in Table 2 and discussed below.

12. Export Preparation Costs: In general, precedent recognizes that it is appropriate that any comparison between foreign and domestic log prices for purposes of identifying and measuring an asserted countervailable subsidy be adjusted for intervening costs and quality differences that would sustain cross-border price differences even in the absence of LERs (see the next argument below). Through a complicated and hard (for the Canadians) to explain and measure process of sorting logs for export, certain costs are borne that arguably require accounting for in the ITA's calculation of asserted subsidies. Nevertheless, the incremental stakes in the issue do not appear to be overwhelming, and 
the ITA can rely on the precedent of "deference to the agency's expertise" in ignoring export preparation costs in its calculations.

13. Transport Costs: In light of the precedent mentioned above, the Canadian parties have been successful in arguing that transport costs should be deducted from foreign-derived $\log$ prices in any attempt under the LER analysis to arrive at $\log$ prices netted back to domestic B.C. markets. The resulting adjustments are relatively minor.

14. Company Exclusions: Under CVD precedent and law, individual companies can be exempted from a countervailing duty if they can be shown to be outside the affected sector or do not use the particular item (B.C. logs, in this case) that is allegedly being subsidized. Such exclusions are not quantitatively important, and the Canadian parties have generally been successful in proving up particular companies for exclusion.

\section{RESULTS}

Having constructed Table 2 from considerations of the foregoing form, it now provides the basis for a Boolean Analysis of the determinants of successful arguments before the ITA. I proceed by converting the indicated zero/one designations to the upper case/lower case notation indicated above and in the Table, and then factoring the resulting expressions into prime implicants. Thus, for example, the first case (Rent Theory) in Table 2 becomes:

$$
\text { DoC/CFLI Win }=\text { pSteX, }
$$

while the second case (LER as Subsidy) becomes:

$$
\text { DoC/CFLI Win }=p S t e x
$$

In words, the first case says that the DoC/CFLI won the argument under conditions in which 
precedent was not particularly in its favor and the stakes were large and the applicable theory was complicated and available evidence did not favor the DoC/CFLI and the DoC/CFLI found it relatively easy to exposit its argument against the Canadian position. Phrased this way, it is clear why individual case studies have such a difficult time yielding clear results; with so many "ands," isolating why the DoC/CFLI won the Rent Theory issue is not possible. But this points to the potential value of the full Boolean Analysis.

Upon fully factoring Table 2, the resulting prime implicant for designation of a winning argument is:

$$
\text { Win }=p S t+P s X[t E+T e]
$$

This is the complete summary of Table 2, and reflects the process of logical reduction described above. ${ }^{23}$ In words, the prime implicant for Win says:

A winning argument before the ITA has either precedent running against it $(p)$ and a complicated theory $(t)$ but large stakes $(S)$; or it has precedent in its favor $(P)$, low stakes $(\mathrm{s})$, and easy exposition $(\mathrm{X})$, and either a combination of a complicated theory $(\mathrm{t})$ but an easy to tell story (E) or a simple theory (T) with a hard to tell story (e).

At first impression, some of these results may appear contradictory or difficult to interpret. For example, the first term in the prime implicant $(\mathrm{pSt})$ says that a winning argument has precedent running against it and weak evidence behind it, but large stakes. This result should not be interpreted to mean that this combination makes for a winning argument, or a higher likelihood of a winning argument than say a combination of pST (which has a simple theory on

23 The case of Relevant Market/1 is treated as an aberration or outlier for the reasons noted above. 
its side, when compared to $\mathrm{pSt}$ ). Rather, the Boolean implicant must be interpreted as merely saying that, when the analysis removes all logical redundancies from Table 2, it is left with pSt as the logically minimum conditions observed when a win arises despite a lack of supportive precedent. The cases under investigation are insufficiently rich to distinguish further between $p$, $\mathrm{S}$, and $\mathrm{t}$ as determinants of a "win" - just as particular quantitative analyses can turn out to lack sufficient data to overcome problems of collinearity among explanatory factors.

Closer inspection of the process of factoring and reduction that produces the prime implicant for Win above reveals that the cases in Table 2 that produce the first term $(\mathrm{pSt})$ in Win are entirely cases in which DoC/CFLI is the winning party. Similarly, the cases which produce the second term in Win (i.e., PsX[tE + Te]) are entirely cases in which B.C. and the Canadian's are the winners of the argument. From this observation comes the key findings of this study.

Just as in the case of familiar large sample, continuous variable regression methods, the researcher may come to the Boolean Analysis of Table 2's data with supportable prior beliefs concerning such matters as the permissible signs of the effects of independent variables, the proper structural form of specification, and, of course, the basic specification of causal explanatory factors to be included in the analysis. Thus, consideration of the fact that the first term in Win (pSt) arises solely from cases in which the DoC/CFLI prevails before the ITA at the point of Final Determination and reasonable expectations as to the causal meaning of explanatory factors, permits further reduction of $\mathrm{pSt}$ to produce a prime implicant for "DoC/CFLI Wins". Specifically, the "p" in pSt is only reasonably interpreted (through the kinds of prior considerations set forth in sections II and III) as a factor to be overcome in pressing an argument. The same interpretation applies to $t$-- the absence of a simple theory in the argument in question. 
In short, $\mathrm{p}$ and $\mathrm{t}$ impede the ability of the DoC/CFLI to win and argument. Hence, the prime implicant for a win by the DoC/CFLI reduces to:

\section{DoC/CFLI Win $=\mathrm{S}$}

In words: based on the cases we are able to observe and capture in Table 2, the only cases in which we observe the DoC/CFLI winning are large stakes cases in which the magnitude of the stakes allowed the DoC/CFLI to overcome institutional impediments to a winning argument. This finding is the prediction of Capture Theory. It says, contrary to the New Institutionalism, that in at least the cases represented here, no evidence is found that large stakes will not permit the influential, capturing party from overwhelming institutional blockades such as the absence of supportive precedent or the absence of a non-complicated theory for one's argument. Having weighed in heavily in my own prior research against straightforward Capture Theory ${ }^{24}$ and in favor of the New Institutionalism, ${ }^{2 s}$ I am surprised by these findings. They could not have been deduced by ruminating on the various instances of ITA decision making represented by Table 2 - i.e., without application of the Boolean Analysis.

The New Institutionalism is not wholly rejected, however. The second term in Win, as noted, arises from cases in which the Canadian parties prevail in their legal arguments before the ITA. Paralleling the prime implicant for DoC/CFLI Win and imposing the priors that neither complicated theory nor weak evidence assist in winning an argument, the prime implicant

24 E.g., Kalt, J.P. and M.A. Zupan, "Capture and Ideology in the Economic Theory of Politics," American Economic Review, June 1984, pp. 279-300.

25 E.g., Cornell, S. and J.P. Kalt, "Where's the Glue?: Institutional and Cultural Foundations of American Indian Economic Development," Faculty Research Working Papers, John F. Kennedy School of Government, Harvard University, May 1991. 
for B.C. Win from Table 2 is:

$$
\text { B.C. } W \text { in }=P s X[t E+T e]=P s X[E+T]
$$

This result says that, if the Canadians (as the less influential party in the CT sense of influential - see above) are to win an argument, they require not only small stakes (s), but also institutional support in the form of supportive precedent (P), easy exposition $(\mathrm{X})$ and either strong evidence (E) or a straightforward theory (T). 


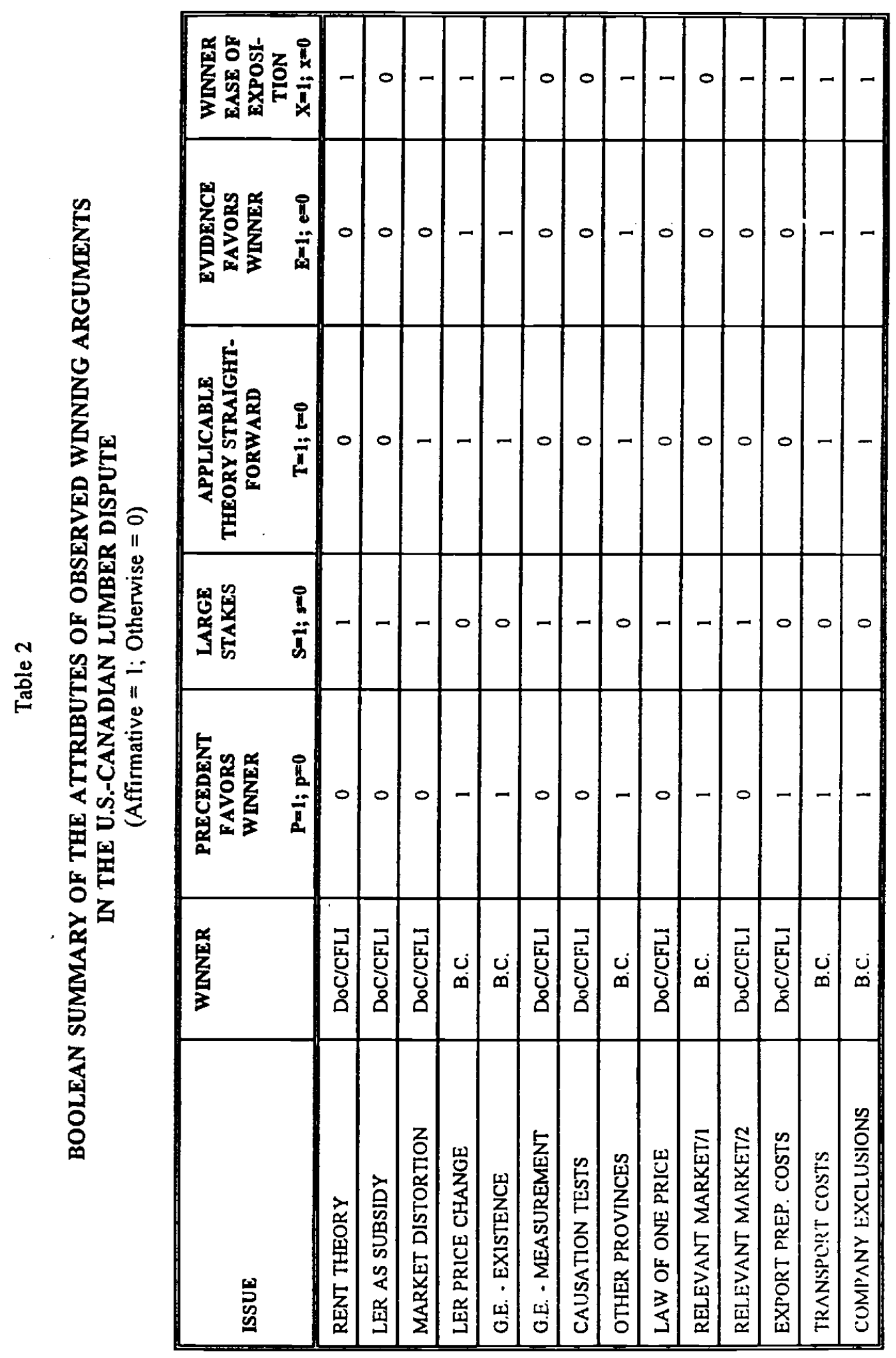

